\title{
LIX. On the development and action of electricity in voltaic combinations
}

\author{
F.W. Mullins M.P. F.S.S. M.R.I.
}

To cite this article: F.W. Mullins M.P. F.S.S. M.R.I. (1837) LIX. On the development and action of electricity in voltaic combinations, Philosophical Magazine Series 3, 10:61, 281-286, DOI: 10.1080/14786443708649143

To link to this article: http://dx.doi.org/10.1080/14786443708649143

册 Published online: 01 Jun 2009.

Submit your article to this journal $₫$

Џ Article views: 2

Q View related articles $₫$ 
by a blow with a hammer, the needle will be deflected, or a spark will appear at the points of the wire, or if connected with the human body a shock will be received. It is obvious, therefore, that the electricity in this circle, at the moment of fracture, is in rapid motion towards a perfectly new state of stable equilibrium. From this new state then the electricity may be easily put in motion by an

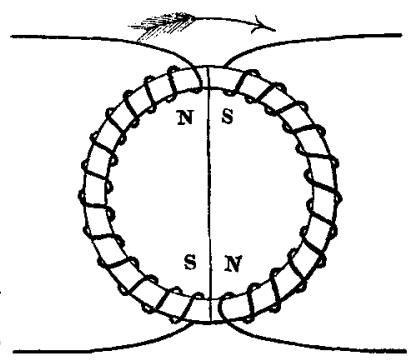
inducing or reacting cause till it approach or finally gain the state of tension which it had before the ring was broken. Hence from what is called a permanent magnet we may obtain as powerful a shock and as brilliant a spark as from a soft iron electro-magnet. If in the common magneto-electric machine a continuous wire be coiled round the ends of the permanent magnet, and a simple flat lifter, without a coil, be made to revolve opposite the poles, an exceedingly brilliant spark, and a shock too powerful to be endured, may be easily produced. If the revolving keeper have also a coil, by joining the ends to form a continuous coil with that on the magnet the effect may be much increased.

Instead of the revolving lifter of soft iron, another permanent horseshoe magnet may be employed with equal or perhaps greater advantage. The result of these arrangements may form the subject of another short communication.

LIX. On the Development and Action of Electricity in Voltaic Combinations. By F. W. Muluins, M.P., F.S.S., M.R.I., \&c.

DOES the development of a certain force or power of voltaic electricity, whether in the production of quantity or intensity effects, depend upon the employment of equal surfaces of zinc and copper? This question has been frequently answered, by some in the affirmative, by others in the negam tive, but the prevailing opinion appears to be in favour of equal quantities of the two metals; and in the various forms of batteries in general use we see such arrangements as give equal metallic surfaces, or nearly so. It is therefore because this point is still in dispute that I make my observations pub-

* Communicated by the Author.

Third Series. Vol, 10. No.61. April 1837. 2 O 
lic; in the belief that the results of a series of experiments, conducted with care and frequently repeated, fully justify me in asserting that every battery in present use, which contains equal surfaces of zinc and copper, is constructed on a wrong principle, and that in such batteries an enormous quantity of zinc is consumed without the slightest advantage. I was first struck by this fact while experimenting with the Wollaston battery, for I always remarked that the zinc plates were unequally corroded, the action being much greater within an inch of the lower edge of the plates than higher up. I also found that after using these plates for some time, when of course the original extent of surface was much diminished, the power of the battery was quite as great as at first, assuming that the plates were clean and the battery fresh charged. In consequence of these observations I reduced the size of the zinc plates to a fourth of what they had previously been, and could not perceive the least diminution in effect; so that without any greater action in a given time on that part of the zinc which I retained, I was enabled to develop the same power, thereby avoiding the waste caused by the action of the solution on the remaining parts of the larger plates. Having thus satisfied myself that a large quantity of zinc absolutely went for nothing in the common batteries, I entered upon a new series of experiments on the same subject with my sustaining battery, which, in consequence of its power not diminishing, gave me a certainty of still more accurate and satisfactory results than I could have hoped to obtain from a battery whose power was unequal. In order that others who may be prejudiced in favour of equal metallic surfaces may have an opportunity of convincing themselves of the truth of what has been stated, I think it may be well to give them an account of a few of the experiments made with the sustaining battery, which they may perform without any difficulty.

One of the tests of which I availed myself was the magnetic voltameter, which, for the measurement of small quantities of electricity or of that of low tension, is, without doubt, as accurate an instrument as any we know. In these instruments there is of course this defect, that no two of them will, for the same quantity or force of electricity, afford the same indication in degrees, which arises from difference in the size of the needles, length and number of coils, thickness of the wire, \&c.; but where the same instrument is applied in the comparison of different effects, it is, as I before stated, as perfect as any with which we are acquainted. If then we connect this instrument with one of my small cylinder batteries, the copper in 
which is about five inches high, and is surrounded by a zinc cylinder one fourth of the surface of the copper*, the needle will be deflected to an angle of, say $75^{\circ}$ : now, if we remove the first cylinder of zinc and substitute another of twice its surface, we shall find no increased deflection, and therefore no increase of quantity. In like manner, if we go on enlarging the zinc surface until at length it equals that of the copper, the indication of the needle will still be the same, and this though we have added a large proportion of the two solutions for the purpose of bringing the entire zinc and copper into contact with the fluids. So far I agree with Mr. Daniell, who also uses small surfaces of zinc; but in prosecuting this experiment it will appear that I differ as much from that gentleman's conclusions, if he says that a thin wire of zinc, or a piece of zinc reduced to the smallest proportions, will produce no diminution of power, as in the former part of the same experiment 1 differed from Marianini, who asserted that the copper should be at least eight times the surface of the zinc in order to produce the maximum effect; for if instead of increasing the zinc surface we now reduce that which was first used, the needle will then diminish its angle and go on retrograding in proportion as the zinc is reduced, thus showing that there is a certain proportion between the zinc and copper surfaces which produces the greatest power. Again, with an electro-magnet of sufficient size, the battery described, when in proper order, will lift two hundred weight; add the larger zincs until you bring the surfaces equal; the lifting power is no greater than at first. Again, take one of my intensity-sustaining batteries, which consists of three zinc and three copper cylinders one within the other; apply this instrument to the magnetic voltameter, which will give an angle of $86^{\circ}$; then apply it to Faraday's decomposition voltameter, and the quantity of the gases produced will be found to be exactly the same, whether the small cylinders of zinc be used or larger ones equal in surface to the copper, and the needle will indicate no greater deflexion in the one case than in the other. Fully convinced, therefore, by the results of these and many other experiments too numerous to detail here, that zinc plates or cylinders about one fourth of the surface of the copper, produce fully as great an effect as if the surfaces were equal, I strongly recommend any student of this branch of science, if he still has any doubts as to the correctness of my

- It may be well to observe that in charging this battery 1 use two fluids : one consisting of 1 part of saturated solution of muriate of ammonia to 4 of water, in contact with the zinc; the other, a saturated solution of sulphate of copper, in contact with the copper; a bladder, or what is better, if properly managed, white silk, being interposed between the metals. 
results, to experiment for himself before he goes to the additional expense of large quantities of zinc, and of their necessary consequences, increased expenditure of muriate of ammonia and sulphate of copper, or acids, if he prefer using them. 'The mode of action of the sulphate of copper in the voltaic circuit is singular, and appears not to have been noticed by any of those gentlemen who have hitherto used it. 'The opinion seems to be, that in order to keep up the electrical action in regard to quantity as well as tension, it is necessary that the solution should be kept in a state of saturation. This is not the case; the solution does not require the addition of crystals until nearly every particle of copper has been precipitated and the liquid has lost almost all its blue tinge, which fact clearly shows that the effects do not depend upon the quantity of copper in solution, but upon a certain quantity precipitated in a given time, and that so long as that quantity remains to be precipitated, so long is there no diminution of power. In my batteries, which I have often in action for two or three months, I never keep the solution in a state of saturation; and whenever I find that the precipitation has been nearly completed, I can draw off the original charge (of the sulphate) and introduce a fresh supply, without the least interference with the electric action. In cases where crystals are kept in the solution, I have strong grounds for thinking that the action of the liquid on these crystals has a tendency to interfere with the full development of electricity in the solution. It would appear from this peculiar property, if I may so call it, of the sulphate, as well as from the results of many experiments which $I$ hope to detail in a future paper, that a large proportion of the electricity which becomes sensible in this case is produced by the return of the copper to its metallic state, which change obliges it to disengage a certain proportion of the electricity with which it was previously combined in its state of a salt; and further, that the definite proportions of all elements in their various combinations depend upon the proportions of the electric æther with which the material molecules are either accompanied or combined; - that this æther governs the definite proportions of all combinations, no two elements having similar proportions of electricity combining, and those which have different proportions uniting; - that as there is but one electric fluid, if it can be so called, negative electricity is an improper term, less positive being more appropriate;-that electricity is capable of expansion and contraction under certain circumstances; - that in all cases where two or more elements are combined, if the addition of another causes new combinations, separation of one of the original elements, or any other change, 
the element which has been added is either more or less positive than either of the original elements, so that, under such circumstances, the material molecules will be instantly subjected to new attractions, the less positive molecule quitting that for which its attraction was not so strong, and uniting with the other for which it has a greater attraction; - that in proportion to the comparative specific gravities of gases, liquids, and solids, so are the quantities of electricity combined with them,--that element of the gases having the least specific gravity being the most positive, and that having the greatest least so*, and in like manner with liquids and solids; - that heat is merely a property of electricity, becoming sensible in chemical decompositions and combinations, by its disengagement in large quantity and the difficulty of restoring the equilibrium; and this it is which causes a platina wire to become red hot when the electric current is sent through a reduced and different conducting medium. Thus, if we revert to the action of the battery in the precipitation of the sulphate of copper, a new attraction being brought into play, more powerful than that of the oxide for the acid, that union is dissolved, and the metallic molecules being brought into a state of aggregation, do not in their new state attract the same proportions of electricity; the consequence is that a large quantity, like latent heat in cases of condensation, and, indeed, identical with it, is disengaged, and goes to supply the loss of electricity in the circuit.

I believe light, as well as heat, to be a property of electricity, else, how account for its existence in its purest form in vacuo, where electricity is the only agent? But I shall refer to these subjects again and at greater length when I have more leisure than $I$ have at present, merely adding that $I$ do not believe my views to be irreconcilable with Mossotti's theory, and

- As an example, I give a list of a few of the metals, in which I institute a comparison between their specific gravities, their atomic numbers, and their electrical states.

\begin{tabular}{|c|c|c|c|}
\hline & $\mathrm{Sp} . \mathrm{Gr}$ & Atom. No. & Pos. Elec. \\
\hline Potassium & 0.865 & 40 & 1 \\
\hline Sodium ... & 0.972 & 24 & 2 \\
\hline Manganese & $6 \cdot 850$ & 28 & 12 \\
\hline Zinc..... & 6.861 & 34 & 13 \\
\hline Iron $\quad \ldots . .$. & $7 \cdot 788$ & 28 & 15 \\
\hline Nickel ....... & $8 \cdot 279$ & 26 & 16 \\
\hline Cobalt ....... & $8 \cdot 538$ & 26 & 17 \\
\hline Copper $\quad .$. & $8 \cdot 895$ & 64 & 23 \\
\hline Silver ....... & $10 \cdot 474$ & 100 & 24 \\
\hline Platinum... & 20.98 & 96 & 97 \\
\hline
\end{tabular}


that I am quite satisfied that though chemical action may be supposed to develop electricity, still electricity itself is the prime mover; electrical and material attractions and repulsions, when brought into play by certain arrangements of elements, inducing and creating all chemical phænomena.

February 7,1837 .

F. W. Mulirns.

\section{Reviews, and Notices respecting Nerw Books.}

The Human Brain, its configuration, structure, development, and physiology; illustrated by references to the nervous system in the lower orders of animals. By SAMUeL SoLLy, Lecturer on Anatomy and Physiology in St. Thomas's Hospital. London, 1836, 12mo.

TPHIS work of Mr. Solly professes to treat of the development and structure of the human brain as illustrated by a reference

to the central portions of the nervous system of the lower animals. We have perused the work with much attention, and no inconsiderable degree of gratification, and are free to confess that the object proposed has been faithfully accomplished. A systematic work of this description has been much wanted as a class-book in our medical schools, where the anatomy of the brain is almost invariably taught as if the organ consisted of isolated fragments of cerebral matter having no communication with each other. Mr. Solly, as a teacher of anatomy at St. Thomas's Hospital, has of late years been in the habit of illustrating his lectures on this subject by continually placing before the student the analogues of many parts of the brain in other animals, and has thrown an interest into this branch of the subject, which as treated before was dry and insipid.

The first part of the work treats of the nervous system of the lower animals, and proceeds to the consideration of that of animals of a higher grade, having more especially in view the law by which masses of 'neurine,' termed ganglia, are concentrated, in proportion to the higher development of the senses of the animals. To il ustrate this part of his subject, amongst many other interesting points, the author has adduced the anatomy of the nervous system of the moth, and has shown the progressive development of the organism from the larva to the imago, " and the striking increase in the size, and the greater complexity in the form of the nervous system, when the animal becomes fitted to receive impressions from the objects which surround it, which it does through the nedium of especial organs of sense."

Mr. Solly has in the elucidation of this part of his subject borrowed largely from the labours of other naturalists, but bis extracts from the works of others are faithfully acknowledged.

The anatomy of the human brain forms the next division of his subject, and his method of dissecting the organ accords with that of Reil and Spurzheim. The anatomy is strict and minute, and our auther has made us acquainted with some new facts connected with the intricate structure of this complex organism. His description of the fornix as the " inferior longitudinal commissure," differs in some points from that of other authors, and is illustrated 